\title{
PENGARUH KUALITAS PELAYANAN DAN KUALITAS PRODUK TERHADAP KINERJA PERUSAHAAN DI LARISSA AESTHETIC CENTER DENPASAR
}

\author{
Ni Ketut Pega Vidananda ${ }^{1}$ \\ Putu Yudi Setiawan'
}

\author{
${ }^{1}$ Fakultas Ekonomi dan Bisnis Universitas Udayana, Bali, Indonesia \\ email: vidanandapega@gmail.com
}

\begin{abstract}
ABSTRAK
Penelitian ini memiliki tujuan agar pengaruh kualitas pelayanan serta kualitas produk pada kinerja perusahaan dapat diketahui. Penelitian ini dilaksanakan kepada pelanggan salah satu klinik kecantikan di Bali, yaitu Larissa Aesthetic Center Denpasar. Sampel yang digunakan yakni 100 responden dengan metode purposive sampling. Data didapatkan melalui mendistribusikan kuesioner. Teknik analisis datanya yaitu regresi berganda melalui SPSS. Hasil mengindikasikan kualitas pelayanan memberi pengaruh positif signifikan akan kinerja perusahaan serta kualitas produk memberi pengaruh positif signifikan akan kinerja perusahaan. Berdasarkan hasil penelitian diharapkan manajemen perusahaan dapat lebih memerhatikan kegiatan operasional perusahaan melalui kontribusi karyawan dalam memberikan pelayanan dan memperhatikan kandungan dan komposisi bahan baku produk, serta ketepatan pengaplikasian produk pada saat proses treatment untuk lebih memuaskan pelanggan sehingga penilaian kinerja perusahaan dapat lebih baik lagi.
\end{abstract}

Kata kunci: kualitas pelayanan; kualitas produk; kinerja perusahaan

\begin{abstract}
This research aimed to determine the effect of service quality and product quality on firm performance. This research was done on customers of Larissa Aesthetic Center Denpasar, which is an aesthetic clinic in Bali. The sample's used were 100 respondents that was chosen by purposive sampling method. Data collection is done by using questioners. The technique for analyzing the data is multiple regression with SPSS. The research's result indicated that service quality has positive and significant effect on business performance and product quality has positive and significant effect on business performance. Based on the results, hopefully the management could pay more attentions to the operational activities through the contribution of each employees in order to give a good service and pay more attention to the content and composition of product's raw materials, as well as the accuracy of product application during the treatment process to the customers, so that the customers will more satisfy and the business performance assessment could be even better.
\end{abstract}

Keywords: service quality; product quality; firm performance 


\section{PENDAHULUAN}

Sebagai bagian dari pasar kosmetik yang tergolong cukup besar, Indonesia memiliki prospek bisnis yang cukup menjanjikan. Tercatat adanya 797 industri kosmetik besar serta IKM di Indonesia hingga tahun 2018 (Kemenperin, 2018). Pertumbuhan industri ini di dukung pasar domestik yang bagus dengan bertambahnya populasi generasi milenial. Adanya pengaruh sosial budaya turut berperan menciptakan perubahan gaya hidup baru di masyarakat, bahwa penampilan dianggap penting untuk meningkatkan kepercayaan diri. Penampilan yang dimaksud bukan hanya melalui fashion style yang up-to-date dan menggunakan peralatan make-up untuk terlihat menawan tetapi kesehatan kulit juga menjadi aset yang berharga. Sehingga personal care dengan perawatan kulit mulai menjadi trend untuk membuat kulit menjadi lebih sehat, segar, dan terlihat bersinar. Tidak heran apabila trend menggunakan skincare dan pergi ke klinik kecantikan ikut terus bertumbuh di industri ini.

Larissa Aesthetic Center ialah 1 dari 10 klinik kecantikan terdepan di Indonesia (indeksnews.com, 2020). Demi menyambut peluang bisnis di industri ini sekaligus merebut perhatian konsumen, Larissa Aesthetic Center dengan mengusung konsep "Natural Ingredient with High Technology" yakni sistem perawatan berbahan alami yang disinergikan dengan teknologi modern hadir menawarkan varian treatment dan produk skincare dengan harga terjangkau (Larissa.co.id, 2020) untuk memenuhi kebutuhan konsumen.

Hingga saat ini Larissa Aesthetic Center telah memiliki 37 kantor cabang yang tersebar di 17 kota di wilayah Indonesia. Daerah terserbu antara lain Yogyakarta, Solo, Semarang, Klaten, Purwokerto, Tegal, Salatiga, Surabaya, Malang, Kediri, Denpasar, Magelang, Madiun, Sragen, Mojokerto, Kudus, dan Ponorogo.

Khususnya di wilayah Bali, Larissa Aesthetic Center cabang Denpasar menjadi salah satu klinik yang ramai dikunjungi oleh konsumen untuk melakukan perawatan kulit (facial treatment). Ramainya pengunjung tidak berarti klinik ini luput dari keluhan pelanggan. Berdasarkan hasil ulasan google dari komentar pelanggan masih ada beberapa keluhan karena kurang puas atas pelayanan dan produk yang diterima. Keluhan yang dimaksud, antara lain terkait ketidak pastian waktu tunggu dari yang dijanjikan, keluhan mengenai pelayanan customer service, urutan antrian untuk mendapat tindakan treatment, serta beberapa review terkait efek samping dan keandalan produk yang digunakan pelanggan sebagai tindak lanjut setelah treatment (google.com/larissa+aesthetic+center+denpasar, 2020).

Dalam mengukur kinerja perusahaan, puas atau tidaknya pelanggan digunakan sebagai bahan evaluasi bagi manajemen terkait kesesuaian yang didapatkan antar harapan pelanggan dengan kinerja aktual pelayanan yang diterima serta hasil yang diberikan produk setelah pemakaian. Keluhan pelanggan dapat menjadi masalah yang serius bagi perusahaan apabila tidak ditangani dengan baik. Bukan tidak mungkin pelanggan dapat beralih ke tempat lainnya agar mendapat kualitas yang lebih baik dan dirasa lebih memuaskan. Mengingat persaingan bisnis di bidang ini sangat kompetitif. Demi meminimalisir keluhan maka perlu bagi perusahaan untuk lebih memerhatikan kinerja melalui pemberian 
kualitas yang lebih baik dimana akan mengarah pada kepuasan pelanggan dan akhirnya berpengaruh pada penilaian kinerja perusahaan.

Istilah kinerja sering digunakan untuk menunjukkan hasil pengelolaan yang dicapai oleh suatu perusahaan (Stainler, 2006; Setiawan dan Gestanti, 2018). Kinerja diartikan sebagai proses membandingkan antara hasil kerja terhadap standar yang ditetapkan oleh perusahaan secara terukur yang mampu menggambarkan kondisi empirik perusahaan (Prasetya et al. (2019).

Secara konseptual, kinerja dapat dilihat dari dua sisi, yaitu kinerja organisasi dan kinerja individu. Kinerja organisasi adalah total dari hasil kerja yang dicapai oleh organisasi, sedangkan kinerja individu merupakan hasil kerja karyawan atau perseorangan anggota perusahaan. Pada dasarnya kinerja individu dan organisasi berhubungan erat satu sama lain (Lestari dan Warmika, 2019).

Mahsun (2006:25) memberikan konsep kinerja, yaitu sebagai suatu proses penilaian kemajuan pekerjaan terhadap tujuan dan sasaran yang telah ditentukan sebelumnya, termasuk informasi atas efisiensi penggunaan sumber daya dalam menghasilkan barang dan jasa, kualitas barang dan jasa (seberapa baik barang dan jasa diserahkan kepada konsumen dan sampai seberapa jauh konsumen terpuaskan); hasil kegiatan dibandingkan dengan maksud yang diinginkan; dan efektivitas tindakan dalam mencapai tujuan. Pengukuran kinerja perusahaan penting dilakukan oleh manajemen sebagai bahan evaluasi kegiatan operasional perusahaan sehingga dapat merefleksikan ide dan pemikiran baru untuk pencapaian yang lebih optimal di masa mendatang.

Pengukuran kinerja perusahaan tidak hanya dapat dilihat dari perspektif keuangan sebagai tolak ukur keberhasilan perusahaan. Melalui pendekatan Balance Scorecard, yaitu model pengukuran kinerja secara komprehensif, terdapat tiga perspektif lain yang digunakan untuk mengukur kinerja perusahaan. Tiga perspektif non-keuangan lainnya yaitu customer, internal processes, dan learning and development.

Salah satu perspektif non-keuangan yang berkontribusi penting adalah perspektif pelanggan. Dapat dilihat dari kemampuan untuk mendapatkan kepercayaan pelanggan, kemampuan mempertahankan pelanggan lama dan pelayanan kepada pelanggan (Alimudin et al., 2017). Perspektif pelanggan menentukan bagaimana proses bisnis internal tercapai yang di dalamnya terdapat indikator-indikator pelayanan yang telah memiliki standar, produk yang memuaskan konsumen dan layanan retur pembelian (Alimudin dan Yoga, 2015).

Dalam perspektif pelanggan (customer), indeks kepuasan pelanggan menjadi salah satu indikator pengukuran kinerja untuk menilai baik-buruknya kinerja suatu perusahaan (Barnes, 2008:404). Pengukuran ini digunakan dalam penelitian terdahulu yang dilakukan oleh Suta dan Dwiastuti (2016); Jannah et al. (2018). Puas tidaknya pelanggan menentukan penilaian kinerja perusahaan dan tingkat keluhan yang dirasakan pelanggan. Hasil penelitian Putri et al. (2017) dan Jeremy (2018) turut menyatakan hasil bahwa kepuasan pelanggan berpengaruh signifikan terhadap kinerja perusahaan.

Menurut Olowokudejo dan Oladimeji (2019), guna memaksimalkan kinerja, perusahaan harus mampu mengimplementasikan strategi-strategi yang dapat menciptakan nilai baik untuk perusahaan maupun pelanggan. Hal ini bisa 
dilaksanakan dengan memberikan kepuasan pada kebutuhan, keinginan serta selalu memberi perhatian pada selera pelanggan (Lestari dan Warmika 2019). Melalui pengelolaan kualitas pelayanan dan kualitas produk bisa dilakukan sebagai salah satu cara untuk memastikan bahwa perusahaan memiliki keunggulan dalam memenuhi keinginan pelanggan dan pencapaian tujuan perusahaan (Awino et al. (2018).

Kualitas ialah faktor penting yang berkaitan dengan kinerja perusahaan. Kualitas diartikan sebagai kesesuaian antar produk (barang atau jasa) dan spesifikasi kebutuhan pelanggan. Pelanggan membutuhkan produk berbentuk barang ataupun jasa yang mampu memberi performa terbaik. Kian tinggi kesesuaiannya dengan spesifikasinya, kian tinggi pula kualitas produk ataupun jasa terkait. Kualitas yang tinggi dapat memberikan kontribusi besar terhadap kepuasan pelanggan serta memberi keunggulan bersaing perusahaan yang nantinya memberi pengaruh pada kinerja perusahaan (Hartini, 2012). Dalam penelitian oleh Forkeret al. (1996); Golhar dan Deshpande (1999), menyatakan bahwa kualitas produk serta kualitas pelayanan yang baik mengarah kepada kinerja perusahaan yang lebih baik.

Kualitas pelayanan teridentifikasi sebagai salah satu fitur utama yang pada akhirnya mengarah pada keberhasilan perusahaan dari segi kepuasan konsumen dan kinerja perusahaan (Latif et al. 2016) pada perusahaan jasa. Hal ini sesuai dengan hasil penelitian yang dilakukan oleh Dennisa dan Santoso (2016); Worodiyanti (2016); Setiawan dan Sayuti (2017); Dewi dan Sudiartha (2018); Fauzi dan Mandala (2019), bahwa kualitas pelayanan berpengaruh terhadap kepuasan pelanggan.

Pelayanan didefinisikan sebagai suatu kegiatan atau urutan kegiatan yang terjadi dalam transaksi langsung antara seseorang dengan orang lain (dalam hal ini yang dimaksud antara karyawan perusahaan dengan pelanggan) atau mesin yang secara fisik berperan dalam memenuhi kebutuhan pelanggan. Menurut Kotler dan Keller (2007:180), kualitas pelayanan adalah keseluruhan fitur dan sifat produksi atau pelayanan yang berpengaruh pada kemampuan untuk memuaskan kebutuhan yang dinyatakan secara tersirat. Dalam penelitian Tsietsi dan Last (2017), kualitas pelayanan merupakan hasil dari interaksi antara manusia yang berperan sebagai penyedia layanan kepada konsumen, dimana kualitas pelayanan berpengaruh terhadap keseluruhan kinerja perusahaan terutama pada industri jasa.

Jika kualitas pelayan sebuah perusahaan baik, penilaian seseorang terkait perusahaan juga akan baik, yang membuat orang akan percaya. Beberapa penelitian menyatakan hasil penelitian pengaruh antara kualitas pelayanan akan kinerja perusahaan. Kualitas pelayanan memberi pengaruh positif signifikan akan kinerja perusahaan dinyatakan dalam hasil penelitian Sani (2017); Awino et al. (2018); Fitriyani (2018); Olowokudejo dan Oladimeji (2019). Namun, hal berbeda dinyatakan dalam hasil penelitian Nwokah (2008); Caruana et al. (2010); serta Putri et al. (2017), bahwa kualitas pelayanan tak memberi pengaruh kinerja perusahaan.

$\mathrm{H}_{1}$ : Kualitas pelayanan berpengaruh positif serta signifikan pada kinerja perusahaan. 
Kualitas produk turut menjadi hal yang memicu respon pelanggan untuk dievaluasi lebih lanjut oleh manajemen perusahaan. Produk merupakan segala sesuatu yang dihasilkan oleh produsen untuk kemudian ditawarkan ke pasar dengan tujuan untuk mendapatkan perhatian, digunakan dan dikonsumsi dengan harapan dapat memenuhi kebutuhan atau keinginan konsumen (Kotler dan Amstrong, 2016:256). Kualitas produk merupakan kesesuaian produk dengan spesifikasi atau standar yang ditetapkan pelanggan, dalam hal ini harapan pelanggan. Hal ini dapat berupa proses dan bahan baku yang digunakan dalam pembuatan produk. Semakin tinggi kesesuaian spesifikasi dan keandalan yang diberikan suatu produk berarti semakin tinggi kualitas produk tersebut.

Puas tidaknya pelanggan terhadap kualitas produk yang diberikan dinilai dari kinerja produk dalam memenuhi kebutuhan dan harapan pelanggan. Didukung oleh hasil dari beberapa penelitian terdahulu, antara lain Dennisa dan Santoso (2016); Kurnia (2016); Razak et al. (2016); Wijaya dan Nurcaya (2017), bahwa kualitas produk berpengaruh positif signifikan terhadap kepuasan pelanggan.

Selain mempengaruhi kepuasan pelanggan, tingginya kualitas produk memberikan keunggulan dalam persaingan perusahaan yang juga memberi dampak kinerja perusahaan. Hasil penelitian Henard dan Szymanski (2001); Kevin et al. (2008); Cannatelli et al. (2015); Yang dan Ju (2017); dan Jonga et al. (2018), menyatakan kualitas produk memiliki pengaruh signifikan pada kinerja perusahaan. Namun pernyataan berbeda ditemukan pada penelitian Tracey dan Tan (2001), bahwa kualitas produk tidak memiliki pengaruh langsung terdahap kinerja perusahaan.

$\mathrm{H}_{2}$ : Kualitas produk berpengaruh positif serta signifikan pada kinerja perusahaan.

Kerangka konseptual adalah kerangka hubungan antara konsep-konsep yang akan diteliti dan diukur melalui penelitian yang akan dilakukan. Untuk mengetahui hbungan antara kualitas pelayanan, kualitas produk, sera kinerja perusahaan pada penelitian ini digambarkan menjadi:

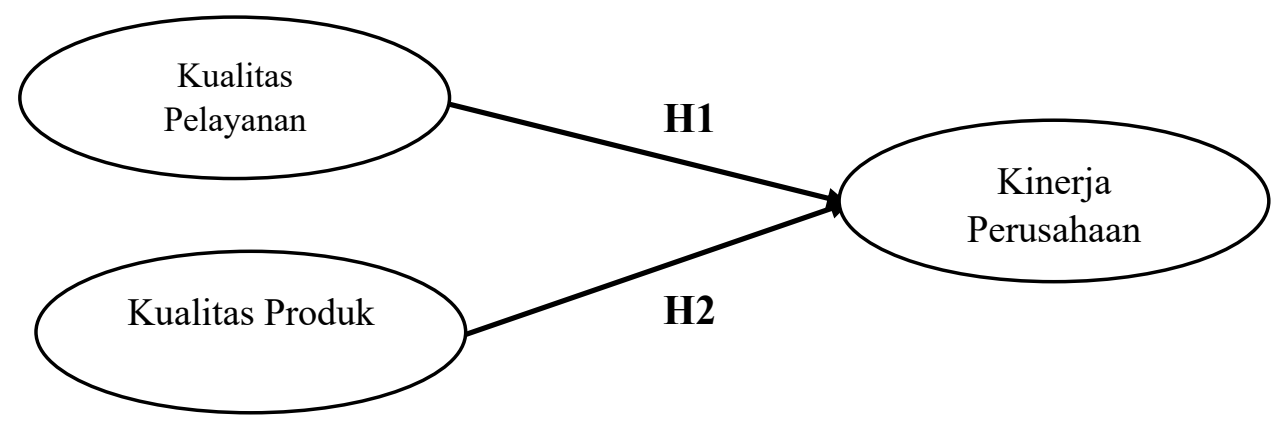

Gambar 1. Kerangka Konseptual 


\section{METODE PENELITIAN}

Penelitian ini merupakan penelitian asosiatif dengan pendekatan kuantitatif. Penelitian asosiatif dilaksanakan agar pengaruh dua variabel ataupun lebih dapat diketahui (Sugiyono, 2017:20). Pendekatan kuantitatif diartikan sebagai metode penelitian yang berlandaskan pada filsafat positivisme, digunakan untuk meneliti pada populasi atau sampel tertentu, pengumpulan data menggunakan instrument penelitian, analisis data bersifat kuantitatif/ statistik, dengan tujuan untuk menggambarkan dan menguji hipotesis yang telah ditetapkan (Sugiyono, 2017:23).

Penelitian dilakukan pada klinik kecantikan Larissa Aesthetic Center Denpasar yang merupakan 1 dari 37 kantor cabang Larissa Aesthetic Center yang tersebar di 17 kota di wilayah Indonesia. Berlokasi di Kec. Denpasar Barat, Kota Denpasar. Pemilihan lokasi didasarkan pada masih adanya keluhan pelanggan terhadap pelayanan juga pasca pemakaian produk Larissa yang digunakan sebagai daily routine.

Objek yang diteliti adalah kualitas pelayanan, kualitas produk serta kinerja perusahaan. Kualitas pelayanan $\left(\mathrm{X}_{1}\right)$ serta kualitas produk $\left(\mathrm{X}_{2}\right)$ selaku variabel bebas sekaligus kinerja perusahaan (Y) sebagai variabel terikat. Secara lengkap, masing-maisng variabel serta indikator dipaparkan menjadi:

Tabel 1.

Variabel dan Indikator

\begin{tabular}{|c|c|c|c|c|}
\hline Variabel & Dimensi & Indikator & & Sumber \\
\hline Kualitas & Tangibles & Tempat bersih & $\mathrm{X} 1.11$ & Olowokudejo \\
\hline \multirow[t]{14}{*}{ Pelayanan } & & Karyawan berpenampilan rapi & $\mathrm{X} 1.12$ & dan Oladimeji \\
\hline & & Fasilitas tertata rapi & $\mathrm{X} 1.13$ & (2019) \\
\hline & Empathy & Memahami pelanggan & $\mathrm{X} 1.21$ & \\
\hline & & Sabar mendengarkan pelanggan & $\mathrm{X} 1.22$ & \\
\hline & & Waktu beroperasi nyaman & $\mathrm{X} 1.23$ & \\
\hline & Reliability & Waktu sesuai janji & $\mathrm{X} 1.31$ & \\
\hline & & Biaya sesuai janji & $\mathrm{X} 1.32$ & \\
\hline & & Tindakan sesuai procedure & $\mathrm{X} 1.33$ & \\
\hline & Responsiveness & Cepat menanggapi pelanggan & $\mathrm{X} 1.41$ & \\
\hline & & Cekatan menanggapi pelanggan & $\mathrm{X} 1.42$ & \\
\hline & Assurance & Informasi mudah dimengerti & $\mathrm{X} 1.51$ & \\
\hline & & Informasi jelas & $\mathrm{X} 1.52$ & \\
\hline & & Ramah melayani pelanggan & $\mathrm{X} 1.53$ & \\
\hline & & Sopan melayani pelanggan & $\mathrm{X} 1.54$ & \\
\hline \multirow{6}{*}{$\begin{array}{l}\text { Kualitas } \\
\text { Produk }\end{array}$} & Kandungan Bahan Baku & Ampuh mengatasi keluhan & $\mathrm{X} 2.11$ & Dennisa dan \\
\hline & & Hasil sesuai manfaat & $\mathrm{X} 2.12$ & Santoso (2016) \\
\hline & Bebas Efek Samping & Tidak ada efek samping & $\mathrm{X} 2.21$ & \\
\hline & & Tidak ketergantungan & $\mathrm{X} 2.22$ & \\
\hline & Daya Tahan Produk & Tidak mudah rusak & $\mathrm{X} 2.31$ & \\
\hline & & Mudah disimpan & $\mathrm{X} 2.32$ & \\
\hline \multirow{4}{*}{$\begin{array}{l}\text { Kinerja } \\
\text { Perusahaan }\end{array}$} & Effectiveness & Treatment ampuh & Y1.1 & Ramayah et al. \\
\hline & & Produk ampuh & Y1.2 & (2011); Jannah \\
\hline & Efficiency & Uang sesuai hasil & Y 2.1 & et al. (2018) \\
\hline & & Waktu sesuai hasil & Y 2.2 & \\
\hline
\end{tabular}

Bersambung... 
Lanjutan Tabel 17.

\begin{tabular}{lllrl}
\hline Variabel & \multicolumn{1}{c}{ Dimensi } & \multicolumn{1}{c}{ Indikator } & Sumber \\
\hline & & & & \\
& Productivity & Pelayanan konsisten & Y3 & \\
& Customer Satisfaction & Puas dengan hasil & Y4.1 & \\
& & Puas dengan produk & Y4.2 & \\
\hline
\end{tabular}

Sumber: Adaptasi jurnal penelitian sebelumnya, disusun 2020

Adapun jenis datanya yakni data kuantitatif, berupa data penilaian (scoring) terhadap tanggapan responden dari hasil kuesioner yang disebar. Skala Likert digunakan sebagai kriteria penentuan skor dalam mengisi pernyataan kuesioner dan berupa data kualitatif, yaitu berupa data informasi mengenai data diri responden. Penentuan skor dilakukan sebagai berikut:

STS : Sangat Tidak Setuju, skor 1

TS : Tidak Setuju, skor 2

$\mathrm{N} \quad$ : Netra, skor 3

S : Setuju, skor 4

SS : Sangat Setuju, skor 5

Sumber data menggunakan data primer dan data sekunder. Data primer berasal dari responden berupa hasil jawaban kuesioner mengenai variabel penelitian dan data sekunder yang berasal dari institusi atau pihak lain yang mempublikasikan data/informasi terkait.

Populasi adalah keseluruhan element yang akan dijadikan wilayah generalisasi, terdiri dari objek/subyek yang memiliki kuantitas dan karakteristik tertentu yang ditetapkan oleh peneliti untuk dipelajari dan kemudian ditarik kesimpulannya (Sugiyono, 2017:443). Populasi yang digunakan adalah masyarakat Kota Denpasar yang pernah menikmati pelayanan serta menggunakan produk Larissa Aesthetic Center sebagai kelanjutan treatment sesuai dengan keluhan dan jenis kulit.

Sampel adalah bagian dari jumlah dan karakteristik yang dimiliki oleh populasi tersebut (Sugiyono, 2017:137). Adapun sampel dipilih dengan teknik non-probability sampling serta metode purposive sampling, yaitu penarikan sampel berdasarkan tujuan dari peneliti dilihat dari pertimbangan informasi yang dibutuhkan (judgment sampling). Karena jumlah populasi yang tak diketahui, adapun jumlah sampel diukur melalui rumus unknown population (Frendy, 2011:53):

$$
n=Z^{2} / 4 \mu^{2}
$$

Ket:

$\mathrm{n} \quad=$ ukuran sampel

$\mathrm{Z} \quad=$ tingkat keyakinan sampel yang dibutuhkan (pada $\alpha=5 \%$ atau derajat keyakinan ditentukan 95\% maka $Z=$ $1,96)$

$\mu \quad=$ margin of error, tingkat kesalahan yang bisa ditolerir 
(ditentukan 10\%)

Maka diperoleh perhitungan:

$\mathrm{n}=\mathrm{Z}^{2} / 4 \mu^{2}$

$\mathrm{n}=1,96^{2} / 4(0,1)^{2}$

$\mathrm{n}=96,4=97$ responden

Adapun sampel yang digunakan yakni 97 responden, namun tak terdapat aturan pasti dalam menetapkan presentasi banyaknya sampel. Sehingga banyaknya sampel penelitian dibulatkan menjadi 100 responden yang dianggap mewakili.

Teknik analisi data adalah model regresi linear berganda dengan SPSS. Model ini diterapkan agar pengaruh kualitas pelayanan serta kualitas produk akan kinerja perusahaan dapat diketahui. Menurut Sugiyono (2017:305) analisis regresi ganda diaplikasikan jika peneliti ingin meramalkan keadaan variabel dependen, bila dua ataupun lebih variabel independen selaku factor predictor dimanipulasi. Analisis regresi berganda dilaksanakan bila jumlah variabel independen paling sedikit 2. Persamaan regresi yang digunakan yaitu:

Persamaan regresi untuk dua prediktor:

$$
\mathrm{Y}=\alpha+\beta_{1} \mathrm{X}_{1}+\beta_{2} \mathrm{X}_{2}+\mathrm{e} \text {. }
$$

Ket:

$\mathrm{Y} \quad=$ Kinerja Perusahaan

$\alpha \quad=$ Konstanta

$\beta_{1} \beta_{2}=$ Koefisien regresi variabel $\mathrm{X}_{1} \mathrm{X}_{2}$

$\mathrm{X}_{1} \quad=$ Kualitas Pelayanan

$\mathrm{X}_{2} \quad=$ Kualitas Produk

$\mathrm{e} \quad=$ Variabel pengganggu

Uji statistik F pada dasarnya menunjukkan apakah semua variabel independen yang dimasukkan dalam model memiliki pengaruh secara bersamasama terhadap variabel dependen. Uji $\mathrm{F}$ dilakukan dengan membandingkan signifikansi $\mathrm{F}_{\text {hitung }}$ dengan $\mathrm{F}_{\text {tabel. }} \mathrm{F}_{\text {tabel }}$ didapat dengan cara $=(\mathrm{k} ; \mathrm{n}-\mathrm{k})$.

Pengujian koefisien determinasi bertujuan untuk mengetahui besarnya pengaruh antar variabel. Nilai koefisien determinasi menunjukkan presentasi variasi nilai variabel dependen yang dapat dijelaskan oleh persamaan regresi yang dihasilkan.

Model regresi digunakan dengan tujuan memprediksi variable terikatnya (Y). Dengan tujuan menghindari hasil yang bias, memerlukan uji asumsi klasik agar hasil yang didapatkan valid serta tak bertentangan dengan asumsi-asumsi metode kuadrat terkecil, yakni BLUE ("Best, Linear, Unbias Estimator"). Adapun uji asumsi klasik diantaranya: 1) Uji Normalitas, 2) Uji Multikolinearitas, 3) Uji Heteroskedastisitas, dan 4) Uji Autokorelasi (Utama, 2016:99). Uji hipotesis dilaksanakan dengan melakukan uji t.

Uji normalitas dipakai untuk melihat distribusi model regresi variabel dependen serta independen. Model yang paling baik yakni terdistribusi normal ataupun setara normal. Uji normalitas dilaksanakan melalui One-Sample Kolmogorov-Smirnov disebut normal bila Asymp Sig $>0.05$. 
Uji Multikolinearitas dipakai dalam melihat kemiripan satu variabel independent dengan variabel independent lainnya pada satu model. Model regresi yang baik sepatutnya tak berkorelasi pada variabel independennya. Agar mengetahui keberadaan multikolinearitas, yaitu melalui nilai tolerance atau VIF, yaitu terdapat multikolinearitas jika nilai Tolerance $<0,10$ (nilai VIF $>10$ ) dan tak terdapat multikolinearitas jika nilai Tolerance $>0,10$ (nilai VIF $<10$ ).

Uji Heteroskedastisitas dipakai melihat penyimpangan model dikarenakan adanya gangguan dari variabel lainnya pada satu observasi ke observasi lainnya. Agar mengetahui heteroskedastisitas ataupun tidak, bisa dilihat dengan nilai signifikansi. Bila nilai signifikanci $>0.05$, disebut tak heteroskedastisitas.

Uji t dilakukan untuk menguji masing-masing koefisienn regresi mengenai signifikan tidaknya pengaruh dari masing-masing variabel bebas terhadap variabel terikat. Berkaitan dengan hal ini, uji signifikan secara parsial digunakan untuk menguji hipotesis peneliti.

\section{HASIL DAN PEMBAHASAN}

Data karakteristik responden adalah profil dari 100 responden yang didapat dalam pengumpulan data dengan penyebaran kuesioner, terdiri atas nama, jenis kelamin, usia, pendidikan terakhir serta penghasilan perbulan.

Tabel 2.

Karakteristik Responden

\begin{tabular}{|c|c|c|c|}
\hline No & Karakteristik & Klasifikasi & Jumlah \\
\hline \multirow[t]{3}{*}{1} & Jenis Kelamin & Laki-laki & 12 \\
\hline & & Perempuan & 88 \\
\hline & Jumlah & & 100 \\
\hline \multirow[t]{6}{*}{2} & Usia (tahun) & $18-24$ & 67 \\
\hline & & $25-31$ & 24 \\
\hline & & $32-38$ & 3 \\
\hline & & $39-45$ & 2 \\
\hline & & $\geq 46$ & 4 \\
\hline & Jumlah & & 100 \\
\hline \multirow[t]{5}{*}{3} & Pendidikan Terakhir & SMA/SMK/Sederajat & 53 \\
\hline & & Diploma & 13 \\
\hline & & $\mathrm{S} 1$ & 34 \\
\hline & & Pascasarjana & 0 \\
\hline & Jumlah & & 100 \\
\hline \multirow[t]{6}{*}{4} & Pekerjaan & Mahasiswa & 49 \\
\hline & & Karyawan Swasta & 38 \\
\hline & & PNS & 1 \\
\hline & & Wiraswasta & 3 \\
\hline & & Yang Lain & 9 \\
\hline & Jumlah & & 100 \\
\hline \multirow[t]{4}{*}{5} & Penghasilan Perbulan & $<$ Rp 5 juta & 85 \\
\hline & & Rp 5 juta - Rp 10 juta & 13 \\
\hline & & $>$ Rp 10 juta & 2 \\
\hline & Jumlah & & 100 \\
\hline
\end{tabular}

Sumber: Data primer, diolah 2020

Tabel 2. mengindikasikan kategori responden berdasarkan jenis kelamin yang mana mayoritas responden berjenis kelamin perempuan yakni 88 orang, 
sedangkan laki-laki sebanyak 12 orang dari 100 responden. Kriteria usia didominasi oleh responden berusia 18-24 tahun sebanyak 67 orang dari 100 responden diikuti oleh responden berusia 25-31 tahun sebanyak 24 orang. Kriteria pendidikan terakhir responden mayoritas SMA/SMK/Sederajat sebanyak 53 orang, diikuti jenjang pendidikan Strata 1 (S1) sebanyak 34 orang dari 100 orang responden. Pada kriteria pekerjaan didominasi oleh responden sebagai mahasiswa dan karyawan swasta secara berturut-turut dengan angka sebesar 49 orang dan 38 orang dari 100 responden. Kriteria terakhir yaitu penghasilan perbulan didominasi oleh responden berpenghasilan $<\mathrm{Rp} 5.000 .000$ yakni 85 orang.

Uji instrumen memakai uji validitas serta uji reliabilitas. Uji validitas bertujuan agar mengetahui bahwasanya instrumen penelitian valid, sehingga bisa dipakai dalam mengukur indikator penelitian. Instrumen disebut valid jika memenuhi kriteria nilai signifikan $<0.05$ dan $r_{\text {hitung }}>r_{\text {tabel }}$. Pada penelitian ini nilai $\mathrm{r}_{\text {tabel }}$ yakni 0.361 . Sedangkan uji reliabilitas bertujuan agar mengetahui konsistensi dari alat ukur penelitian. Pada penelitian ini menggunakan teknik Alpha Cronchbach. Instrumen disebut reliabel jika koefisien korelasi $>0,60$.

Tabel 3.

Hasil Uji Validitas

\begin{tabular}{|c|c|c|c|c|c|c|}
\hline \multirow[t]{2}{*}{ Variabel } & \multicolumn{4}{|c|}{$\mathbf{r}_{\text {hitung }}$} & \multirow[t]{2}{*}{ Sig } & \multirow[t]{2}{*}{ Ket } \\
\hline & \multicolumn{2}{|l|}{ Dimensi } & \multicolumn{2}{|c|}{ Indikator } & & \\
\hline Kualitas & Tangibles & 0.762 & $\mathrm{X}_{1.11}$ & 0.894 & 0.000 & Valid \\
\hline Pelayanan & & & $\mathrm{X}_{1.12}$ & 0.827 & 0.000 & Valid \\
\hline \multirow[t]{13}{*}{$\left(\mathrm{X}_{1}\right)^{\prime}$} & & & $\mathrm{X}_{1.13}$ & 0.935 & 0.000 & Valid \\
\hline & Empathy & 0.904 & $\mathrm{X}_{1.21}$ & 0.839 & 0.000 & Valid \\
\hline & & & $\mathrm{X}_{1.22}$ & 0.870 & 0.000 & Valid \\
\hline & & & $\mathrm{X}_{1.23}$ & 0.908 & 0.000 & Valid \\
\hline & Reliability & 0.846 & $\mathrm{X}_{1.31}$ & 0.755 & 0.000 & Valid \\
\hline & & & $\mathrm{X}_{1.32}$ & 0.853 & 0.000 & Valid \\
\hline & & & $\mathrm{X}_{1.33}$ & 0.712 & 0.000 & Valid \\
\hline & Responsiveness & 0.780 & $\mathrm{X}_{1.41}$ & 0.690 & 0.000 & Valid \\
\hline & & & $\mathrm{X}_{1.42}$ & 0.704 & 0.000 & Valid \\
\hline & Assurance & 0.860 & $\mathrm{X}_{1.51}$ & 0.908 & 0.000 & Valid \\
\hline & & & $X_{1.52}$ & 0.899 & 0.000 & Valid \\
\hline & & & $\mathrm{X}_{1.53}$ & 0.837 & 0.000 & Valid \\
\hline & & & $\mathrm{X}_{1.54}$ & 0.792 & 0.000 & Valid \\
\hline \multirow{6}{*}{$\begin{array}{l}\text { Kualitas } \\
\text { Produk } \\
\left(\mathrm{X}_{2}\right)\end{array}$} & Kandungan Bahan & 0.773 & $\mathrm{X}_{2.11}$ & 0.950 & 0.000 & Valid \\
\hline & Baku & & $\mathrm{X}_{2.12}$ & 0.947 & 0.000 & Valid \\
\hline & Bebas Efek Samping & 0.765 & $\mathrm{X}_{2.21}$ & 0.900 & 0.000 & Valid \\
\hline & & & $\mathrm{X}_{2.22}$ & 0.865 & 0.000 & Valid \\
\hline & Daya Tahan Produk & 0.814 & $\mathrm{X}_{2.31}$ & 0.891 & 0.000 & Valid \\
\hline & & & $\mathrm{X}_{2.32}$ & 0.857 & 0.000 & Valid \\
\hline \multirow{4}{*}{$\begin{array}{l}\text { Kinerja } \\
\text { Perusahaan } \\
(\mathrm{Y})\end{array}$} & Effectiveness & 0.856 & $\mathrm{Y}_{1.1}$ & 0.919 & 0.000 & Valid \\
\hline & & & $\mathrm{Y}_{1.2}$ & 0.929 & 0.000 & Valid \\
\hline & Efficiency & 0.841 & $\mathrm{Y}_{2.1}$ & 0.906 & 0.000 & Valid \\
\hline & & & $\mathrm{Y}_{2.2}$ & 0.904 & 0.000 & Valid \\
\hline
\end{tabular}

Bersambung.......... 
Lanjutan Tabel 3.

\begin{tabular}{|c|c|c|c|c|c|c|}
\hline \multirow[t]{5}{*}{ Variabel } & \multicolumn{4}{|c|}{$\mathbf{r}_{\text {hitung }}$} & \multirow[t]{2}{*}{ Sig } & \multirow[t]{2}{*}{ Ket } \\
\hline & \multicolumn{2}{|l|}{ Dimensi } & \multicolumn{2}{|c|}{ Indikator } & & \\
\hline & Productivity & & & 0.872 & 0.000 & Valid \\
\hline & Customer Satisfaction & 0.906 & $\mathrm{Y}_{4.1}$ & 0.839 & 0.000 & Valid \\
\hline & & & $Y_{4.2}$ & 0.917 & 0.000 & Valid \\
\hline
\end{tabular}

Sumber: Hasil olah data primer, 2020

Berdasarkan hasil perhitungan Pearson Product Moment untuk uji validitas menunjukkan semua indikator variabel penelitian valid dikarenakan telah memenuhi kriteria uji validitas, yaitu nilai signifikan seluruh variabel ditunjukkan dengan angka $0,000<0,05$ dan $\mathrm{r}_{\text {hitung }}>\mathrm{r}_{\text {tabel, }}$, dengan rentang nilai 0,762 - 0,906 yang berarti $>0,361$, jadi instrument penelitian valid untuk digunakan.

Angka $\mathrm{r}$ hitung terbesar didapat pada dimensi customer satisfaction pada variabel kinerja perusahaan sebesar 0,906 , sedangkan angka $r_{\text {hitung }}$ terkecil didapat pada dimensi tangibles pada variabel kualitas pelayanan sebesar 0,762.

Tabel 4.

Hasil Uji Reliabilitas

\begin{tabular}{lllll}
\hline \multicolumn{2}{c}{ Variabel } & \multicolumn{2}{c}{ Nilai Alpha } & \multirow{2}{*}{ Keterangan } \\
\cline { 1 - 3 } $\begin{array}{llll}\text { Kualitas } \\
\text { Pelayanan }\end{array}$ & 0.882 & Tangibles & 0.863 & \\
& & Empathy & Reliabel \\
& & Reliability & 0.841 & Reliabel \\
& & 0.660 & Reliabel \\
& & Responsiveness & 0.901 & Reliabel \\
Kualitas & Assurance & 0.882 & Reliabel \\
Produk & \multirow{2}{*}{0.669} & Kan. Bahan Baku & 0.889 & Reliabel \\
& & Bebas Efek Samping & 0.713 & Reliabel \\
Kinerja & \multirow{2}{*}{0.885} & Daya Tahan Produk & 0.689 & Reliabel \\
Perusahaan & Effectiveness & 0.872 & Reliabel \\
& & Efficiency & 0.779 & Reliabel \\
& & Cust. Satisfaction & 0.690 & Reliabel \\
\hline
\end{tabular}

Sumber: Hasil olah data primer, 2020

Hasil uji reliabilitas memperlihatkan nilai Alpha Cronbach dari semua variabel penelitian dengan rentang nilai $0,669-0,885$, yang berarti telah memenuhi kriteria pengujian karena nilai hasil $>0,60$, instrument dinyatakan reliabel. Nilai terbesar ditunjukkan pada nilai variabel kinerja perusahaan, sedangkan nilai terendah pada variabel kualitas produk. Oleh sebab itu kuesioner penelitian dianggap reliabel dan konsisten sebagai alat ukur penelitian.

Analisis model regresi linear berganda dilakukan dengan SPSS bertujuan agar pengaruh kualitas pelayanan serta kualitas produk pada kinerja perusahaan dapat diketahui.

$$
\begin{aligned}
& \hat{\mathrm{Y}}=0.172 \mathrm{X}_{1}+0.711 \mathrm{X}_{2} \\
& \mathrm{~S}(\beta)=(0.109)(0.084)
\end{aligned}
$$




$$
\begin{array}{ll}
\mathrm{t} & =(2.108)(8.715) \\
\mathrm{Sig} & =(0.038)(0.000) \\
\mathrm{R}^{2} & =0.718 ; \mathrm{df}=97 ; \mathrm{F}=123.364 ; \mathrm{Sig}=0.000
\end{array}
$$

Adapun hasil analisis sebagai berikut:

Hasil perhitungan $\mathrm{F}$ menunjukkan angka sebesar 123,364, dengan signifikansi $0,000<0,05$ yang bermakna secara serempak variabel kualitas pelayanan $\left(\mathrm{X}_{1}\right)$ serta kualitas produk $\left(\mathrm{X}_{2}\right)$ memberi pengaruh pada kinerja perusahaan (Y).

Hasil hitung koefisien determinasi berganda $\left(\mathrm{R}^{2}\right)$ adalah 0,718 yang bermakna keberadaan naik turunnya kinerja perusahaan diberi pengaruh oleh kualitas pelayanan serta kualitas produk sebesar 71,8 persen, lalu sisanya 28,2 persen diberi pengaruh oleh faktor lainnya.

Berdasarkan hasil analisis regresi linear berganda maka didapatkan persamaan regresi sebagai berikut:

$$
\mathrm{Y}=0.172 \mathrm{X}_{1}+0.711 \mathrm{X}_{2}
$$

Keterangan:

$$
\begin{array}{ll}
\mathrm{Y} & =\text { Kinerja Perusahaan } \\
\mathrm{X}_{1} & =\text { Kualitas Pelayanan } \\
\mathrm{X}_{2} & =\text { Kualitas Produk }
\end{array}
$$

Nilai koefisien positif artinya $\mathrm{X}_{1}$ berpengaruh positif terhadap $Y$. Nilai sig variabel $\mathrm{X}_{1}$ sebesar 0,038 lebih kecil dari 0,05 maka artinya terdapat pengaruh signifikan $\mathrm{X}_{1}$ terhadap kinerja perusahaan $\mathrm{Y}$.

Nilai koefisien positif artinya $\mathrm{X}_{2}$ berpengaruh positif terhadap kinerja $\mathrm{Y}$. Nilai sig variabel $\mathrm{X}_{2}$ sebesar 0,000 lebih kecil dari 0,05 maka artinya terdapat pengaruh signifikan $\mathrm{X}_{1}$ terhadap $\mathrm{Y}$.

Dari hasil analisis tersebut, hal ini berarti bahwa kualitas produk $\left(\mathrm{X}_{2}\right)$ mempunyai pengaruh yang dominan terhadap kinerja perusahaan $(\mathrm{Y})$, dapat dilihat dari nilai kontribusi regresi linear berganda dan nilai beta sebesar 0.711 satu satuan.

Nilai Asymp. Sig. (2-tailed) uji Kolmogorov Smirnov $=0.150$

Hasil olah data uji normalitas memperlihatkan nilai Asym. Sig 2 tailed $0,150>0,05$ sehingga data tersebut normal.

\section{Tabel 5.}

\section{Uji Multikolinearitas}

\begin{tabular}{lcc}
\hline \multicolumn{1}{c}{ Variabel bebas } & Tolerance & VIF \\
\hline Kualitas Pelayanan & 0.438 & 2.286 \\
Kualitas Produk & 0.438 & 2.286 \\
\hline
\end{tabular}

Sumber: Hasil olah data primer, 2020 
Adapun hasil pengolahan data uji multikolinearitas menunjukkan nilai tolerance variabel kualitas pelayanan serta kualitas produk yakni $0,438>0,10$, serta nilai VIF yakni $2,286<10,00$, sehingga dari hasil data terkait bisa dikatakan model regresi tak mengalami gejala multikolinearitas.

Tabel 6.

Uji Heteroskedastisitas

\begin{tabular}{lll}
\hline BVariabel bebas & $\mathbf{t}$ & Sig. \\
& & \\
\hline Kualitas Pelayanan & 1.760 & 0.082 \\
Kualitas Produk & -0.693 & 0.490 \\
& \\
\hline Sumber: Hasil olah data primer, 2020
\end{tabular}

Adapun hasil olah data uji heteroskedastisitas menunjukkan kualitas pelayanan memiliki Sig. 0,082 > 0,05 serta kualitas produk memiliki Sig. 0,490> 0,05. Hal tersebut bermakna pada model regresi tak ditemukan gejala heterokedastisitas.

Uji t dilakukan dalam menguji pengaruh antar variabel kualitas pelayanan $\left(\mathrm{X}_{1}\right)$ serta kualitas produk $\left(\mathrm{X}_{2}\right)$ pada kinerja perusahaan $(\mathrm{Y})$ dengan kriteria yang ada yakni:

$$
\begin{gathered}
\mathrm{t}_{\text {hitung }}>\mathrm{t}_{\text {tabel }} \\
\text { nilai signifikansi }<0,05
\end{gathered}
$$

Cara mengetahui $t_{\text {tabel }}$ dapat dilihat di tabel distrbusi $t(n-2)$ signifikansi 0,05 . Berdasarkan hasil uji $t$ yang dapat dilihat pada hasil analisis regresi linear berganda menerangkan bahwa:

Pada variabel kualitas pelayanan $\left(\mathrm{X}_{1}\right)$ adapun nilai $\mathrm{t}$ hitung $>\mathrm{t}$ tabel yakni 2.108 $>1,66$ serta tingkat signifikansinya $0,002<0,05$. Hal tersebut berarti kualitas pelayanan memberi pengaruh positif signifikan pada kinerja perusahaan.

Hasil terkait selaras dengan bunyi hipotesis satu $\left(\mathrm{H}_{1}\right)$ penelitian ini, yaitu "kualitas pelayanan berpengaruh positif serta signifikan pada kinerja perusahaan" dan mendukung hasil penelitian terdahulu oleh Ramayah et al. (2011); Cheng dan Lin (2014); Sani (2017); Fitriyani (2018); Awino et al. (2018); dan Olowokudejo dan Oladimeji (2019) yang menemukan bahwasanya kualitas pelayanan memberi pengaruh positif signifikan pada kinerja perusahaan. Hal tersebut menjelaskan kian baik kualitas pelayanan perusahaan pada pelanggan, penilaian kinerja perusahaan juga semakin baik.

Pada variabel kualitas produk $\left(\mathrm{X}_{2}\right)$ memiliki nilai $\mathrm{t}$ hitung $>\mathrm{t}$ tabel yakni 8.715 $>1,66$ serta signifikansi $0,000<0,05$. Hal tersebut berarti kualitas produk memberi pengaruh signifikan pada kinerja perusahaan. 
Hasil ini selaras dengan bunyi hipotesis dua $\left(\mathrm{H}_{2}\right)$, yaitu "kualitas produk memberi pengaruh positif serta signifikan pada kinerja perusahaan" sekaligus mendukung hasil penelitian terdahulu oleh Henard dan Szymanski (2001); Kevin et al. (2008); Cannatelli et al. (2015); Yang dan Ju (2017); dan (Jonga et al. (2018), bahwa kualtas produk berpengaruh terhadap kinerja perusahaan. Hal tersebut membuktikan bahwasanya kian baik kualitas produk yang didapatkan pelanggan saat pemakaian/pengaplikasian produk maka penilaian kinerja perusahaan akan semakin baik.

Terdapat dua cakupan dari implikasi penelitian, yaitu implikasi teoritis dan implikasi praktis. Implikasi teoritis berkaitan dengan kontribusi hasil penelitian terhadap perkembangan teori mengenai pengaruh kualitas pelayanan dan kualitas produk terhadap kinerja perusahaan. Sedangkan implikasi praktis berhubungan dengan kontribusi hasil penelitian terhadap kualitas pelayanan dan kualitas produk terhadap kinerja perusahaan di Larissa Aesthetic Center Denpasar.

Implikasi teoritis pada penelitian ini telah mampu memerkaya teori manajemen operasi yaitu untuk melihat kinerja perusahaan melalui variabel kualitas pelayanan dan kualitas produk suatu perusahaan. Hasil penelitian telah mampu memperlihatkan hubungan yang positif serta signifikan kualitas pelayanan pada kinerja perusahaan dan kualitas produk pada kinerja perusahaan.

Sedangkan implikasi praktis pada penelitian ini adalah manajemen perusahaan dapat melakukan pengukuran atau penilaian kinerja perusahaan melalui respon pelanggan terkait effectiveness, efficiency, productivity, dan customer satisfaction yang dirasakan selama melakukan treatment dan pemakaian produk Larissa.

Penerapan kualitas pelayanan dapat dilakukan dengan selalu memperhatikan kerapian, kebersihan tempat dan area pelayanan agar pelanggan selalu merasa nyaman untuk datang dan menghabiskan waktu selama treatment. Selain itu hal yang lebih perlu mendapat perhatian adalah kualitas setiap karyawan dalam melayani pelanggan, yaitu dengan lebih komunikatif dalam menanggapi keluhan dan keinginan pelanggan, selalu memberikan informasi dengan penyampaian yang jelas, mudah dimengerti dan akurat, bersikap sopan dan ramah, serta cekatan.

Penerapan kualitas produk dapat dilakukan dengan selalu memperhatikan kandungan bahan baku yang ada pada setiap varian produk yang ditawarkan sebagai tindak lanjut perawatan setelah melakukan treatmet agar benar-benar membantu dalam mengatasi permasalah kulit yang dialami pelanggam. Memberikan spesifikasi yang akurat pada setiap kemasan agar pelanggan tidak merasa tertipu dengan hasil yang dirasakan karena tidak sesai dengan manfaat yang ditawarkan. Selain itu model kemasan dapat dibuat lebih sederhana, menarik, dan mudah disimpan agar tidak cepat rusak yang akan berakibat memberikan efek yang kurang maksimal. Kemasan dibuat lebih informatif mengenai detail kandungan bahan baku, cara penggunaan dan penyimpanan, serta manfaat yang diberikan.

Berdasarkan penelitian yang dilakukan, terdapat beberapa keterbatasan dalam penelitian ini. Keterbatasan tersebut adalah penelitian hanya dilakukan di daerah Denpasar dengan jumlah sampel yang terbatas sehingga tidak dapat digeneralisasikan. Adanya kemungkinan perubahan terhadap lingkungan dan 
trend membuat adanya kemungkinan perubahan pada hasil penelitian sehingga perlu dilaksanakan penelitian mengenai topik serta hubungan serupa dimasa depan.

\section{SIMPULAN}

Kualitas pelayanan memberi pengaruh secara positif signifikan pada kinerja perusahaan. Hal ini berarti semakin baik kualitas pelayanan yang diberikan oleh perusahaan melalui dimensi kualitas pelayanan (tangibles, empathy, realiability, responsiveness, dan assurance) hasil dari strategi manajemen, kegiatan operasional dan kontribusi karyawan dalam memberikan pelayanan maka akan semakin baik penilaian kinerja perusahaan yang dirasakan dan diberikan oleh pelanggan.

Kualitas produk memberi pengaruh positif signifikan pada kinerja perusahaan. Hal ini berarti semakin baik kualitas produk yang diberikan perusahaan terutama pada kandungan bahan baku, hasil pemakaian produk yang bebas dari efek samping, dan daya tahan produk yang baik maka akan semakin baik penilaian kinerja perusahaan oleh pelanggan hasil dari pemakaian produkproduk Larissa sebagai perawatan lebih lanjut setelah melakukan facial treatment.

Adapun saran yang penulis ingin sampaikan guna membantu pihak manajemen perusahaan terutama dalam upaya meningkatkan kinerja perusahaan Larissa Aesthetic Center Denpasar melalui kegiatan operasional berkaitan dengan kualitas pelayanan serta kualitas produk. Saran ini juga ditunjukkan kepada para peneliti selanjutnya:

Hasil memperlihatkan bahwasanya pada variabel kualitas pelayanan perlu ditingkatkan lagi kegiatan operasional yang berkaitan dengan keandalan terutama dalam hal kepastian waktu. Menambah kapasitas produksi dapat menjadi pertimbangan bagi manajemen. Dapat dilakukan dengan mengevaluasi waktu yang diperlukan untuk setiap treatment berdasarkan jenis treatment yang dipilih oleh pelanggan, fasilitas, alat dan teknologi yang tersedia, jumlah karyawan yang bertugas, dan jumlah rata-rata pengunjung yang datang. Dengan melakukan hal tersebut, penambahan jumlah fasilitas, alat dan teknologi serta jumlah karyawan yang bertugas dapat diatur menjadi lebih optimal, sehingga dapat memberikan informasi waktu lebih akurat dan kualitas pelayanan yang lebih baik.

Hasil memperlihatkan bahwasanya pada variabel kualitas produk perlu memerhatikan kegiatan operasional dalam hal kandungan bahan baku terutama pada hasil/manfaat yang dijanjikan. Berdasarkan hal tersebut manajemen perusahaan dapat menginovasi kandungan produk untuk hasil yang lebih memuaskan, memerhatikan komposisi dengan keluhan pelanggan, serta memberikan saran penggunaan varian produk yang sesuai dengan keluhan/masalah kulit pelanggan sehingga hasil yang diberikan selama pemakaian produk setelah treatment benar-benar mampu mengurangi keluhan kulit yang dialami dan meminimalisir efek samping yang dapat ditimbulkan. Melalui hal tersebut diharapkan pada akhirnya akan mampu memberikan penilaian yang lebih baik terhadap kinerja perusahaan.

Untuk peneliti selanjutnya agar bisa meneliti dengan cakupan lebih luas dengan mengembangkan model penelitian dan menambahkan variabel lain diluar 
penelitian ini yang berkaitan untuk mengukur kinerja perusahaan dari segi manajemen operasi.

\section{REFERENSI}

Alimudin, A., Falani, A.Z., Setiawan, E. dan Arifin, B. (2017). The Use of Fuzzy Logic in Developing Competitiveness Strategy Toward Small and Medium Enterprise (Grocery). Advanced Science Letters, 23(12), hal. 11867-73.

Alimudin, A., dan Yoga, H. (2015). Strategi Peningkatan Loyalitas Pelanggan Pada Usaha Kecil Produk Makanan Ringan Di Surabaya. Sustainable Competitive Advantage, 5(1).

Antony, J.P. dan Bhattacaryya, S. (2010). Measuring Organizational Performance and Organizationall Excellence of SMEs-Part 1: A Conceptual Framework. Measuring Business Excellence, 14(2), hal. 3-11.

Awino, B.A., Ondoro, C.O. dan Abong'o, B.E. (2018). Effects of ServiceQuality Management on Performance of Veinacular Radio Broadcasting Firms in Western Kenya. European Scientific Journal, 14(25).

Barnes, D. (2008). Operations Management: An Internationall Perspective. London: Thomson Learning.

Cannatelli, B., Pedrini, M., dan Grumo, M. (2015). The Effect of Brand Management and Product Quality on Firm Performance: The ItalianCraft Brewing Sector. Journal of Food Products Marketing.

Caruana, A., Pitt, L., dan Edwig, M. (2010). The Market Orientation, Performance Link: The Role of ServiceReliability. The Service Industries Journal, 23(4), hal. 25-41.

Cheng, J. S. dan Lin, Y. C. (2014). Effects of Service Quality on Organizational Performance. PakistanJournal of Statistics, 30(6), hal. 1131-40.

Chowdhury, M. M. H. (2011). Ethical Issues as Competitive Advntage for Bank Management. Humanomics, 27(2), hal. 109-20.

Dennisa, E. A. dan Santoso, S. B. (2016). Analisis Pengaruh Kualitas Produk, Kualitas Layanan, Dan Citra Merek Terhadap Loyalitas Pelanggan Melalui Kepuasan Pelanggan Sebagai Variabel Interverning (Studi Pada Klinik Kecantikan Cosmedic Semarang). Diponegoro Journal of Management, 5(3), hal. 1-13.

Dewi, C. I. A. K. dan Sudiartha, I. G. M. (2018). Pengaruh Kualitas Layanan Dan Kualitas Produk Terhadap Kepuasan Nasabah PT. Bank Pembangunan Daerah Bali. E-Jurnal Manajemen Unud, 7(8), hal. 4539-69.

Fauzi, M. R. dan Mandala, K. (2019). Pengaruh Kualitas Pelayanan, Kualitas 
Produk, Dan Inovasi Produk Terhadap Kepuasan Untuk Meningkatkan Loyalitas Pelanggan. E-Jurnal Manajemen Unud, 8(11), hal. 6741-61.

Fitriyani, S. A. (2018). Pengaruh Sistem Informasi Manajemen Pemasaran, Kualitas Pelayanan Dan Word of Mouth Terhadap Capaian Balance Scorecard Serta Dampaknya Terhadap Kinerja Perusahaan Di Sunrise Mall Mojokerto. Journal of Entrepreneurship, Business Development and Economic Educations Research, 1(2).

Forker, L. B., Vickery, S. K. dan Droge, C. L. M. (1996). The Contribution of Quality to BusinessPerformance. International Journal of Operations dan Production Management, 16(8), hal. 44-62.

Frendy. (2011). Metode Penelitian Untuk Bisnis. Jakarta: Salemba Empat.

Golhar, D. Y. dan Deshpande, S. P. (1999). Productivity Comparisons Between Canadian and USTQM Firms: An Empirical Investigation. International Journal of Quality dan Reliability Management, 16(7), hal. 714-22.

Hartini, S. (2012). Peran Inovasi, Pengembangan Kualitas Produk DanKinerja Bisnis. Jurnal Manajemen dan Kewirausahaan, 14(1), hal. 82-88.

Henard, D. H. dan Szymanski, D. M. (2001). Why Some New Products Are More Successful ThanOthers. Journal of Marketing Research, 38(3), hal. 362-75.

Jannah, R. N., Isharijadi, dan Murwan, J. (2018). Analisis Kinerja Pada PD BPD Bank Daerah Kota Madiun Dengan Pendekatan Balance Scorecard. Forum Ilmiah Pendidikan Akuntasi, 6(2).

Jeremy, N. (2018). Pengaruh Brand Equity Terhadap Kinerja Perusahaan Di PT. Unilever Surabaya. Universitas Widya Kartika.

Jonga, M., Waiganjo, E., dan Njeru, A. (2018). Influence of Product Quality on Organizational Performance of Seed MaizeCompanies in Kenya. Journal of Agricultural Science, 10(5).

Kevin, Z. Z., Li, J. J., Zhou, N., dan Su, C. (2008). Market Orientation, Job Stisfaction, Product Quality, and Firm Performance:Evidence From China. Strategic Management Journal, 29, hal. 985-1000.

Kotler, P. (2010). Principles of Marketing: A South Asian Perspective (thirteen edition). India: Pearson Education.

Kotler, P. dan Amstrong, G. (2016). Principle of Marketing (Edisi Keenam Belas). London: Pearson Education.

Kotler, P. dan Keller, K.L. (2007). Manajemen Pemasaran (Edisi Kedua Belas). Jakarta: PT. Indeks.

Kurnia, D. (2016). Pengaruh Kualitas Produk Terhadap Loyalitas Nasabah 
Melalui Kepuasan Nasabah, Nilai Bagi Nasabah, Dan Reputasi Perusahaan Pada Bank BUMN. UG Jurnal, 10(12).

Latif, K. F., Baloch, Q. B., dan Shahibzada, U. F. (2016). An Empirical Investigation into The Role of Internal Service Quality in Fostering Orgnizational Performance. City University ResearchJournal, 6(2), hal. 32143.

Lestari, N. K. N. D. dan Warmika, I. G. K. (2019). Pengaruh Orientasi Teknologidan Orientasi Pasar Terhadap Kinerja Perusahaan. E-Jurnal Manajemen Unud, 8(11), hal. 6700-6720.

Lima, E. P. de, Costa, S. E. G. da, dan Faria, A. R. (2009). Taking Operations Strategy Into Practive: Developing a Process for Developing Priorities and Performance Measures. International Journal of Production Economics, 122(1), hal. 403-18.

Mahsun, M. (2006). Pengukuran Kinerja Sektor Publik. Yogyakarta: BPFE.

Mandy, M. (2009). The Relationship Between Innovativeness and The Performance of Small andMedium Size Enterprise (SMEs) of Malaysian Manufacturing Sector. International Journal of Management and Innovation, 1(2), hal. 1-14.

Nwokah, N. G. (2008). Strategic Market Orientation and Business Performance: The Study of Food and BeveragesOrganizations in Nigerian. European Journal of Marketing, 42(3/4) hal. 279-86.

Olowokudejo, F. F. dan Oladimeji, M. S. (2019). Influence of Service Quality on Organizational Performance in The Nigerian Financial Service Sector. LASU Journal of Management Science, 5(1), hal. 78-85.

Prasetya, D. I., Handoko, F., dan Vitasari, P. (2019). Pengukuran Kinerja Perusahaan Jasa Transportasi Niaga Darat Menggunakan Metode Baldrige Excellence Framework (Studi Kasus Pada PT. Galena Perkasa Sidoarjo). Jurnal Teknologi dan Manajemen Industri, 5(2).

Putri, E. T, Priono, H., dan Susilowati, E. (2017). Kinerja Badan Jaminan Sosial Dan Kepuasan Pelanggan. Jurnal Ilmiah Ilmu Akuntansi, Keuangan danPajak, 1(1).

Ramayah, T., Samat, N., dan Lo, May-Chiun. (2011). Market Orientation, Service Quality and Organizational Performance in Service Organization in Malaysia. Asia-Pasific Journal of Business Administration, 3(1), hal. 8-27.

Razak, I., Nirwanti, N., dan Triatmanto, B. (2016). The Impact of Product Quality and Price on Customer Satisfaction with the Mediator of Customer Value. Journal of Marketing and Cunsomer Research, 30, hal. 59-68.

Sani, A. A. (2017). Pengaruh Teknologi Ramah Lngkungan Dan Kualitas Pelayanan Terhadap Keunggulan Kompetitif Dan Kinerja Perusahaan. E- 
Jurnal Manajemen Unud, 6(7), hal. 3485-3512.

Setiawan, H. dan Sayuti, A.J. (2017). Effects of Service Quality, Customer Trust and Corporate Image on Customer Satisfaction Adn Loyalty: An Assessment of Travel Agencies Customer in South Sumatra Indonesia. IOSR Journal of Business and Management, 19(5), hal. 31-40.

Setiawan, R. dan Gestanti, L. (2018). CEO Education, Karakteristik Perusahaan Dan Kinerja Perusahaan. Jurnal Ilmu Manajemen, 2(2).

Stainler, L. (2006). "Performance Management and Corporate Social Responsibility: The Strategic Connection. Strategic Change, 15, hal. 253-64.

Sugiyono. (2017). Metodologi Penelitian Bisnis. Bandung: Penerbit Alfabeta.

Suta, I. W. P. dan Dwiastuti, G. A. A. S. A. (2016). Pengukuran Kinerja Dengan Pendekatan Balance Scorecard Pada Kantor Pusat PT.Bank Pembangunan Daerah Bali. Jurnal Bisnis dan Kewirausahaan, 12(1), hal. 32-41.

Toni, A. D. dan Tonchia, S. (2001). Performance Measurement Systems Models, Characteristics andMeasures. International Journal of Operations dan Production Management, 21(1/2), hal. 46-71.

Tracey, M. dan Tan, C.L. (2001). Empirical Analysis of Supplier Selection Adn Involvement, Customer Satisfaction, andFirm Performance. Supply Chain Management: An International Journal, 6(4), hal. 174-88.

Tsietsi, M. dan Last, S. (2017). Customers' Perception of Service Quality and Its Impact on Reputation in the Hospitality Industry. African Journal of Hospitality Tourism and Leisure, 6(3), hal. 1-25.

Tsiotsou, R. H. dan Vlachopoulou, M. (2011). Understanding The Effect of Market Orientation and E-Marketing on Service Performance. Marketing Intelligence and Planning, 29(2), hal. 141-55.

Utama, M. S. (2016). Aplikasi Analisis Kuantitatif: Untuk EkonomiDan Bisnis. Denpasar: CV. Sastra Utama.

Wijaya, I. P. S. A. dan Nurcaya, I. N. (2017). Kepuasan Pelanggan Memediasi Kualitas Produk Dan Kewajaran Harga Terhadap Loyalitas Merek McDonalds Di Kota Denpasar. E-Jurnal Manajemen Unud, 6(3), hal. 153463.

Worodiyanti, N. W. (2016). Pengaruh Kualitas Produk, Harga Dan Kualitas Pelayanan Terhadap Kepuasan Konsumen Di Elladerma Skin Care Malang. e-Journal, 5(1), hal. 23-28.

www.google.com/larissa+aesthetic + center + denpasar (2020)

www.indeksnews.com (2020)

www.kemeperin.go.id (2018) 
Ni Ketut Pega Vidananda, Pengaruh Kualitas Pelayanan...

www.larissa.co.id (2020)

Yang, Y. dan Ju, X. F. (2017). Entrepreneurial Orientation And Firm Performance: Is Product Quality a Missing Link?. Entreprenuership Research Journal. 